\title{
Blockade of Nuclear Factor-Kb (NF-Kb) Pathway Using Bay 11-7082 Enhances Arsenic Trioxide-Induced Antiproliferative Activity in U87 Glioblastoma Cells
}

\author{
Ali Nasrollahzadeh ${ }^{1}$, Majid Momeny ${ }^{2}$, Davood Bashash ${ }^{3}$, Hassan Yousefi ${ }^{4}$, \\ Seyed Asadollah Mousavi ${ }^{1}$, Seyed Hamidollah Ghaffari*1
}

\begin{abstract}
Background: Glioblastoma (GBM), the most aggressive and common form of glioma, accounts for over 13,000 death per year in the United States which indicates the importance of developing novel strategies for the treatment of this fatal malignancy. Although Arsenic trioxide (ATO) hinders the growth and survival of GBM cells, the requirement of concentrations higher than $4 \mu \mathrm{M}$ for triggering apoptotic cell death has questioned its safety profile. Since the NF- $\kappa \mathrm{B}$ signaling pathway plays a crucial role in tumorigenesis and chemo-resistance, targeting this oncogenic pathway may sensitize GBM cells to lower concentrations of ATO.

Methods: Anti-tumor effects of ATO as monotherapy and in combination with Bay 11-7082 were determined using MTT, crystal violet staining, Annexin V/PI staining and scratch assays. Quantitative reverse transcription-PCR (qRT-PCR) analysis was applied to elucidate the molecular mechanisms underlying the anti-tumor activity of this combination therapy.

Results: Our results revealed that ATO and Bay 11-7082 synergistically inhibited the proliferation and survival of GBM cells. Also, it was revealed that NF-kB inhibition using Bay 11-7082 enhanced the inhibitory effects of ATO on migration of GBM cells via suppressing the expression of NF- $\mathrm{kB}$ target genes such as TWIST, MMP2, ICAM-1, and cathepsin B. Furthermore, combination treatment of GBM cells with ATO and Bay 11-7082 significantly induce apoptotic cell death coupled with downregulation of NF- $\kappa B$ anti-apoptotic target genes including Bcl-2 and IAP family members.

Conclusions: Altogether, these findings suggest that combination therapy with ATO and Bay 11-7082 may be a promising strategy for the treatment of GBM.
\end{abstract}

Keywords: Arsenic trioxide (ATO), Bay 11-7082, NF-kB signaling pathway, U87 cells, Apoptosis.

\section{Introduction}

Glioblastoma (GBM) is the most common and aggressive primary malignant brain tumor with an average incidence rate of 3.22 per 100,000 people $(1,2)$. It is estimated that each year over 13,000 patients die from this malignancy in the

United States (3). The standard therapeutic strategy for newly diagnosed GBM includes maximal surgical resection followed by concurrent radiotherapy and chemotherapy (4). Moreover, Bevacizumab, a monoclonal

1: Hematology, Oncology and Stem Cell Transplantation Research Center, Shariati Hospital, School of Medicine, Tehran University of Medical Sciences, Tehran, Iran.

2: Turku Bioscience Centre, University of Turku and Åbo Akademi University, FI-20520, Turku, Finland

3: Department of Hematology and Blood Banking, School of Allied Medical Sciences, Shahid Beheshti University of Medical Sciences, Tehran, Iran.

4: Department of Biochemistry and Molecular Biology, LSUHSC, School of Medicine, New Orleans, USA.

*Corresponding author: Seyed Hamidollah Ghaffari; Tel: +989116198552; E-mail: shghaffari@tums.ac.ir.

Received: 6 Dec, 2021; Accepted: 29 Dec, 2021 
antibody that binds to vascular endothelial growth factor, has been clinically approved for the treatment of recurrent GBM (5). However, despite these advances, the prognosis of GBM remains poor and only $5 \%$ of patients survive more than five years (6) which highlights the necessity of developing new therapeutic strategies for this fatal malignancy.

Arsenic trioxide (ATO), a clinically approved chemotherapy drug for the treatment of acute promyelocytic leukemia (7), has been demonstrated to induce significant antitumor effects in a wide range of solid tumors including liver, lung, and glioma models in vitro and in vivo (8-10). However, one major problem in using ATO as a chemotherapeutic agent in GBM is the requirement of high concentrations for its anti-cancerous effects, which makes it physiologically intolerable for patients (10, 11). Furthermore, the heterogeneous nature of GBM leads to resistance to chemotherapy (12). Therefore, using other therapeutic strategies in combination with chemotherapeutic agents such as ATO may enhance its efficiency against this type of cancer.

There is evidence that activation of NF- $\kappa \mathrm{B}$ signaling pathway is a common event in GBM. It has been demonstrated that elevated levels of nuclear p65 and NF- $\kappa \mathrm{B}$-dependent gene expression have been found in GBM stem-like cells. This activation of $\mathrm{NF}-\kappa \mathrm{B}$ signaling pathway may be a major reason for resistance to therapy in GBM cells (13). In this regard, it has been demonstrated that NF- $\mathrm{BB}$ mediates resistance to radiotherapy and chemotherapy in GBM cells $(14,15)$. For instance, inhibition of NF- $\kappa B$ synergistically enhances the antitumor activity of temozolomide, a first-line chemotherapy drug in the treatment of GBM (16). NF- $\mathrm{KB}$ inhibitors have also been found to overcome cisplatin resistance in GBM cells (17). Altogether, these findings suggest that targeting NF- $\mathrm{kB}$ signaling pathway may be a promising strategy to sensitize GBM cells to low concentrations of ATO.

Bay 11-7082 is a potent inhibitor of NF- $\mathrm{NB}$ signaling pathway and its mechanism of action involves suppressing the phosphorylation of

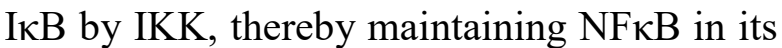
inactive form (18). Several studies have revealed the potential of Bay 11-7082 in combination with various chemotherapeutic agents. We have previously shown that inhibition of NF- $\kappa \mathrm{B}$ signaling pathway using Bay 11-7082 significantly enhances the antiproliferative activity of cisplatin, carboplatin, and paclitaxel in ovarian cancer cells (19). In addition, co-treatment of GBM cells with Bay 11-7082 reverse temozolomide induced significant antitumor effects through induction of apoptotic cell death (16). In the present study, it was investigated whether NF$\kappa \mathrm{B}$ inhibition using Bay 11-7082 sensitizes GBM cells to lower concentrations of ATO.

\section{Materials and Methods \\ Cell lines and drug treatment}

U87 (glioblastoma), OVCAR-3 (originally from ovarian cancer ascites), and PANC-1 (Pancreatic ductal adenocarcinoma) cell lines were purchased from the National Cell Bank of Iran, Pasteur Institute of Iran (Tehran, Iran). All cell lines were maintained at $37^{\circ} \mathrm{C}$ in $5 \%$ $\mathrm{CO} 2$ in a humidified incubator and cultured according to NCBI recommendations, using RPMI with $10 \%$ of fetal bovine serum (FBS) and $1 \%$ Pen-Strep. Arsenic trioxide was purchased from SinaDarou (Tehran, Iran) and diluted in culture medium to produce a stock solution of $0.5 \mathrm{mM}$. Bay 11-7082 was purchased from Adooq Bioscience (Irvine, CA, USA) and was dissolved in DMSO. The final concentrations of DMSO did not exceed $0.1 \%[\mathrm{v} / \mathrm{v}]$ in all the treatments.

\section{Cell viability assay}

MTT assay was performed to evaluate cytotoxic effects of ATO/Bay 11-7082 on cancer cells based on the amount of thiazolyl blue tetrazolium bromide (MTT, Sigma) uptake by viable cells. Briefly, cells were plated in 96-well plates and then treated with different concentrations of ATO $(0,1,2,3,4$, 5, and $6 \mu \mathrm{M})$ and Bay 11-7082 (0, 2.5, 5, 7.5, and $10 \mu \mathrm{M}$ ) alone for $24 \mathrm{~h}$. In combination treatment series, cells were co-treated with Bay 11-7082 (7.5 and $10 \mu \mathrm{M})$ and ATO $(0,1$, 
2, 3, 4, 5, and $6 \mu \mathrm{M}$ ) for $24 \mathrm{~h}$. Then, MTT solution $(0.5 \mathrm{mg} / \mathrm{ml}$ in PBS $)$ was added to each well and the plate was incubated for $4 \mathrm{~h}$ at 37 ${ }^{\circ} \mathrm{C}$. After incubation, the remaining supernatant was removed, and the resulting formazan crystals were solubilized with DMSO. The absorbance of each sample was measured at $570 \mathrm{~nm}$ using a microplate ELISA reader.

\section{Drug combination analysis}

To determine whether there was a synergistic effect between ATO and Bay 11-7082, the combination index $(\mathrm{CI})$ was calculated using CalcuSyn Software based on the method developed by Chou-Talalay (20) and according to the classic isobologram equation: $\mathrm{CI}=(\mathrm{D}) 1 /(\mathrm{Dx}) 1+(\mathrm{D}) 2 /(\mathrm{Dx}) 2$, where $(\mathrm{Dx}) 1$ and (Dx)2 indicate the individual dose of ATO and Bay 11-7082 required to inhibit a given level of viability index, and (D) 1 and (D) 2 are the doses of ATO and Bay 11-7082 necessary to produce the same effect in combination, respectively. The $\mathrm{CI}$ values of $<1,=1$, and $>1$ indicate synergism, additive effect, and antagonism of drugs, respectively. The dose which may be reduced in a combination for a given level of effect as compared to the concentration of individual drug alone is defined as dose reduction index (DRI) and was calculated as follows: (DRI) $1=(\mathrm{Dx}) 1 /(\mathrm{D}) 1$ and $(\mathrm{DRI}) 2=(\mathrm{Dx}) 2 /(\mathrm{D}) 2$. Moreover, to further evaluate the interactions between ATO and Bay 11-7082 the Bliss SynergyFinder was applied to analyze drug combinations (21). An average synergy score of 0 is considered additive, $<0$ as antagonistic and $>0$ as synergistic.

\section{Crystal violet staining}

Cells were seeded at a density of $5 \times 10^{4}$ cells/well in six-well plates and then treated with desired concentrations of the agents for $24 \mathrm{~h}$. Then, the media was removed and the cells were washed with PBS, fixed with icecold methanol and stained with crystal violet solution $(0.5 \% \mathrm{w} / \mathrm{v})$. Cell morphology was evaluated using an inverted microscope.

\section{Wound healing (scratch) assay}

Cells $\left(3 \times 10^{5}\right.$ cells/well) were seeded in 12well plates to reach $80-90 \%$ confluency. After $24 \mathrm{~h}$, the cell monolayer was scraped to create a scratch and then, cells were treated with desired concentrations of ATO and Bay 117082. The first photographs were taken immediately after treatment. After $24 \mathrm{~h}$, another photograph was taken to show the width of the scratch to investigate the effects of the inhibitor on cell migration.

\section{Annexin V/PI apoptosis assay}

Apoptosis analysis was performed using an Annexin V-FITC apoptosis detection kit (Invitrogen). The results were analyzed using a Partec PAS III flow cytometer (Partec) and the Windows ${ }^{\mathrm{TM}}$ FloMax ${ }^{\circledR}$ software (Partec).

\section{Real-time quantitative PCR analysis}

Cells $\left(2 \times 10^{5}\right.$ cells/well) were seeded onto sixwell plates, treated with ATO and Bay 11-7082 for $24 \mathrm{~h}$, and then total RNA was extracted using a highly pure RNA isolation kit (Roche). After quantification of the isolated RNA by a Nanodrop instrument (Nanodrop ND-1000 Technologies), $1 \mu \mathrm{g}$ of RNA from each sample was utilized to synthesize cDNA using PrimeScript RT reagent Kit (TaKaRa, Tokyo, Japan) according to the manufacturer's instructions. Quantitative reverse transcription-PCR (qRT-PCR) analyses were performed using a Light Cycler 96 instrument (Roche Molecular diagnostics). To normalize the expression levels, B2M was used as the housekeeping gene and the mRNA expression was quantified using the $\Delta \Delta C T$ method against the untreated control cells. The list of the used primers is seen in Table 1.

\section{Statistical analysis}

All data were evaluated in triplicate against the vehicle-treated control cells and collected from three independent experiments. Data were graphed and analyzed by GraphPad Prism Software 8.0a using the unpaired two-tailed Student's t-test. All data are presented as mean \pm standard deviation (SD). 
Table 1. Nucleotide sequences of primers used for real-time RT-PCR.

\begin{tabular}{lllll}
\hline Gene & Accession Number & Forward primer & Reverse primer & $\begin{array}{l}\text { Size } \\
\text { (bp) }\end{array}$ \\
\hline B2M & NM_004048.3 & GATGAGTATGCCTGCCGTGT & CTGCTTACATGTCTCGATCCCA & 79 \\
Cathepsin B & NM_000100 & CTGTCGGATGAGCTGGTCAAC & TCGGTAAACATAACTCTCTGGGG & 152 \\
BCL2 & NM_000633 & CGGTGGGGTCATGTGTGTG & CGGTTCAGGTACTCAGTCATCC & 90 \\
MMP2 & NM_001302508 & CTTCCAAGTCTGGAGCGATGT & TACCGTCAAAGGGGTATCCAT & 119 \\
c-IAP1 & NM_001166 & AGCACGATCTTGTCAGATTGG & GGCGGGGAAAGTTGAATATGTA & 102 \\
c-IAP2 & NM_001165 & TCCTGGATAGTCTACTAACTGCC & GCTTCTTGCAGAGAGTTTCTGAA & 160 \\
Survivin & NM_001012270.1 & CCACCGCATCTCTACATTCA & TTTCCTTTGCATGGGGTC & 184 \\
XIAP & NM-001167 & ATAGTGCCACGCAGTCTACAA & AGATGGCCTGTCTAAGGCAAA & 101 \\
ICAM-1 & NM_000201 & AGCTTCGTGTCCTGTATGGC & TTTTCTGGCCACGTCCAGTT & 70 \\
Twist & NM_000474 & GTCCGCAGTCTTACGAGGAG & GCTTGAGGGTCTGAATCTTGCT & 156 \\
\hline
\end{tabular}

\section{Results}

ATO and Bay 11-7082 synergistically inhibit the growth and proliferation of U87 glioblastoma cells

Given the significant regulatory role of NF- $\mathrm{NB}$ signaling pathway in cell survival and tumorigenesis, it was tempting to evaluate the inhibitory effects of Bay 11-7082, an inhibitor of I $\mathrm{KB}$ kinase (IKK), on viability of cancer cells (22). To do so, we exposed a panel of human cancer cell lines including U87 (glioblastoma), OVCAR-3 (originally from ovarian cancer ascites), and PANC-1 (Pancreatic ductal adenocarcinoma) to increasing concentrations of Bay 11-7082. Our results demonstrated that Bay 11-7082 inhibited proliferation of all cancer cell lines in a concentration-dependent manner (Fig. 1a). Based on the results of MTT, the concentrations of $7.5 \mu \mathrm{M}$ and $10 \mu \mathrm{M}$ of Bay 11-7082 were selected for use in combination with ATO. Next, cancer cells were treated with ATO as a single agent and in combination with Bay 11-7082 for $24 \mathrm{~h}$. Here, it was discovered that NF- $\mathrm{BB}$ inhibition using Bay 11-7082 significantly reduced the viability of U87 and OVCAR-3 cells compared to either drug individually (Fig. 1b). However, Bay 11-7082 did not enhance the cytotoxic effects of ATO on PANC-1 cells, suggesting the interaction between ATO and Bay 11-7082 is cell-type specific. Since U87 cells were more sensitive to combination therapy with ATO and Bay 117082, this cell line was selected for further experiments.

To further indicate the stimulatory effects of Bay 11-7082 on antiproliferative activity of ATO in U87 cells, the EC50 shift graph (Fig. 2a). Moreover, to evaluate the interactions between ATO and Bay 11-7082 in U87 cells, Bliss synergy scores were calculated using the SynergyFinder analysis, where we uncovered considerable synergism between drugs (Fig. 2b). To further confirm this, normalized isobologram and $\mathrm{Fa}-\mathrm{CI}$ plots were graphed using CalcuSyn software. As depicted in Figure 2c, all points are below the additive line, suggesting the synergic effects between ATO and Bay 11-7082. Table 2 summarizes the values of DRI and CI after $24 \mathrm{~h}$ for U87 cells. Finally, crystal violet staining was performed to evaluate the effects of ATO/Bay 11-7082 on morphology of U87 cells. We confirmed that combination treatment with ATO and Bay 11-7082 not only decreased the number of viable cells but also altered the morphology of cells compared to either drug individually (Fig. 2d). Collectively, these results suggest that $\mathrm{NF}-\mathrm{\kappa B}$ inhibition using Bay 11-7082 sensitizes U87 glioma cells to ATO. 


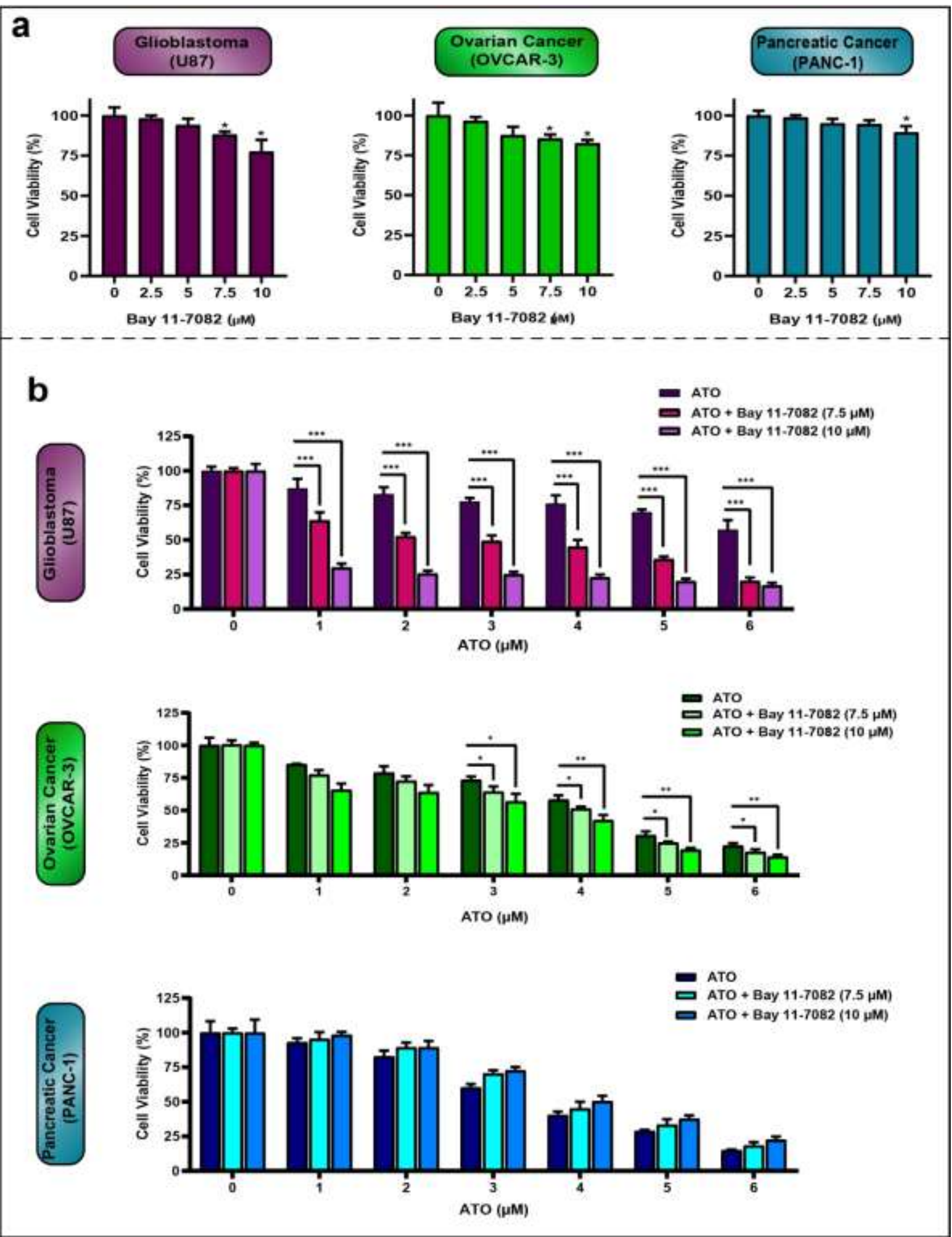

Fig. 1. Inhibitory effects of ATO and Bay 11-7082 on proliferation of cancer cells. (a) The viability of U87 (glioblastoma), OVCAR-3 (originally from ovarian cancer ascites), and PANC-1 (Pancreatic ductal adenocarcinoma) cells was evaluated after exposing to increasing concenfitrations of Bay 11-7082 (0, 2.5, 5, 7.5, and $10 \mu \mathrm{M})$ for $24 \mathrm{~h}$ using MTT assay. (b) U87, OVCAR-3, and PANC-1 cells were treated with designated concentrations of ATO individually and in combination with Bay 11-7082 for $24 \mathrm{~h}$ and cell viability was assessed using MTT assay. Simultaneous exposure to ATO and Bay 117082 caused a significant decrease in the viability of the U87 and OVCAR-3 cells but not in PANC-1 cells, compared to using either drug alone. Values are given as mean \pm SD of three independent experiments. ${ }^{*} \mathrm{p}<0.05, * * \mathrm{p}<0.01$ and $* * * \mathrm{p}<$ 0.001 represents significant changes from untreated control. 


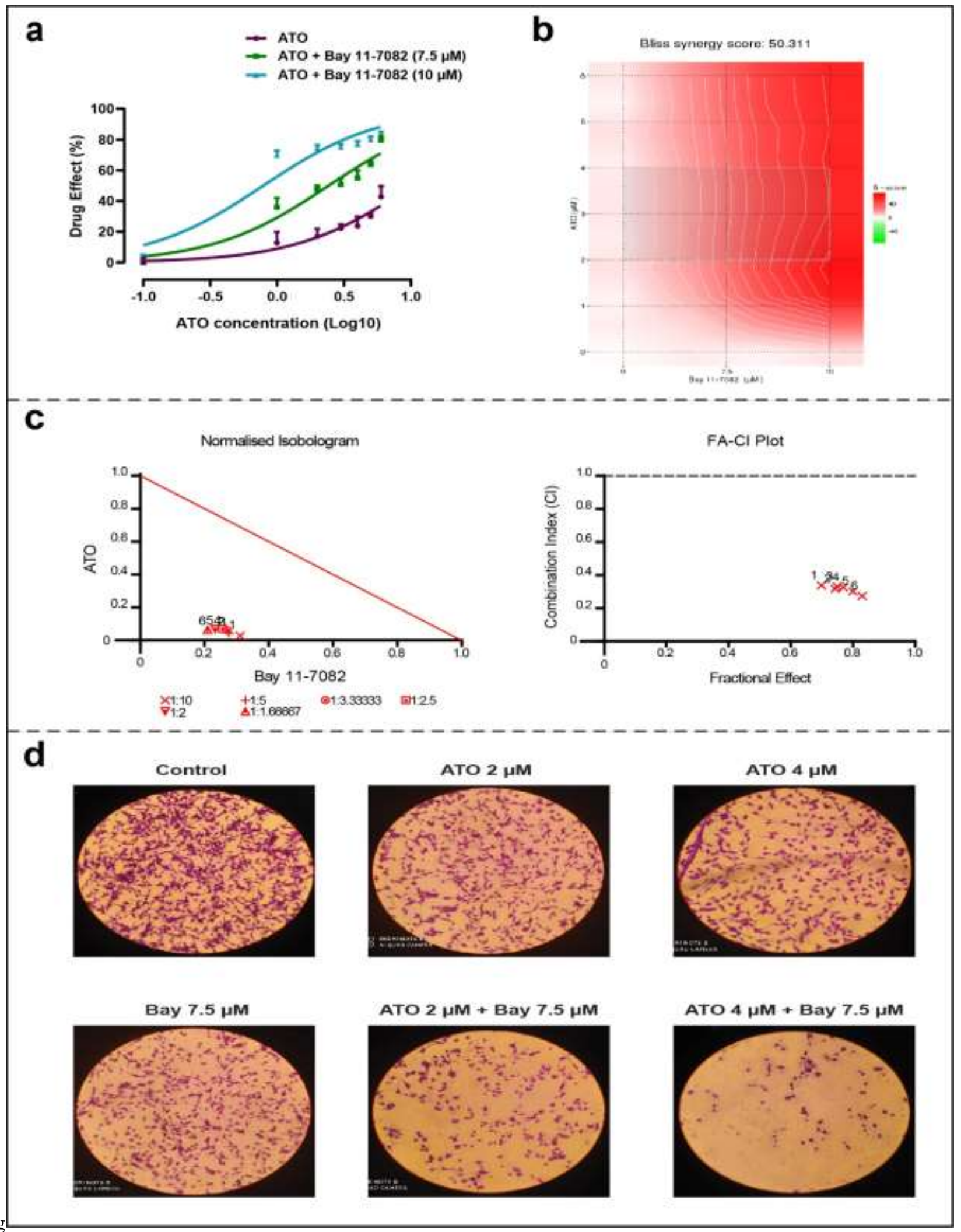

Fig. 2. Synergistic effects of ATO and Bay 11-7082 in U87 cells. (a) Based on the results of MTT assays, the EC50 shift graphs were provided which showed the significant changes in EC50 values (b) The results of Bliss synergy analysis also indicated significant synergistic interactions between ATO and Bay 11-7082 in U87 cells (represented in red). (c) The isobologram and FA/CI plots were drawn using Calcusyn software to show the interaction between two agents. Points below the additive line represent synergism. (d) Crystal violet staining was performed to observe the effects of ATO/Bay 11-7082 on proliferation and morphology of U87 cells. Data are as mean \pm S.D. of three independent experiments. 
Table 2. Combination Index (CI) and Dose Reduction Index (DRI) for drug combination by ATO and Bay 11-7082.

\begin{tabular}{ccccc}
\hline $\begin{array}{c}\text { Bay 11-7082 } \\
\text { Concentration }(\boldsymbol{\mu M})\end{array}$ & DRI & $\begin{array}{c}\text { ATO } \\
\text { Concentration }(\boldsymbol{\mu M})\end{array}$ & DRI & CI \\
\hline 7.5 & 4.290 & 1 & 36.856 & 0.260 \\
7.5 & 4.819 & 2 & 24.167 & 0.249 \\
7.5 & 4.910 & 3 & 16.831 & 0.263 \\
7.5 & 5.205 & 4 & 14.463 & 0.261 \\
7.5 & 5.722 & 5 & 14.428 & 0.244 \\
7.5 & 6.362 & 6 & 15.396 & 0.222 \\
\hline
\end{tabular}

ATO/Bay 11-7082 suppress the motility of U87 cells

Emerging evidence indicates that $\mathrm{NF}-\kappa \mathrm{B}$ signaling pathway plays an important role in promoting invasion and metastasis in GBM cells (23). Therefore, it was tempting to examine whether NF- $\kappa \mathrm{B}$ inhibition using Bay 11-7082 enhances the inhibitory effects of ATO on motility of U87 cells using wound healing assay, a simple laboratory technique to evaluate the effects of drugs on invasion and migration of cancer cells. To conduct this test, a scratch is generated on a cell monolayer to assess the ability of GBM cells to migrate and fill the gap. According to the width of the wounds, combination treatment with ATO and Bay 117082 significantly suppressed invasion and migration of GBM cells compared to treatment with either drug as a single agent (Fig. 3).

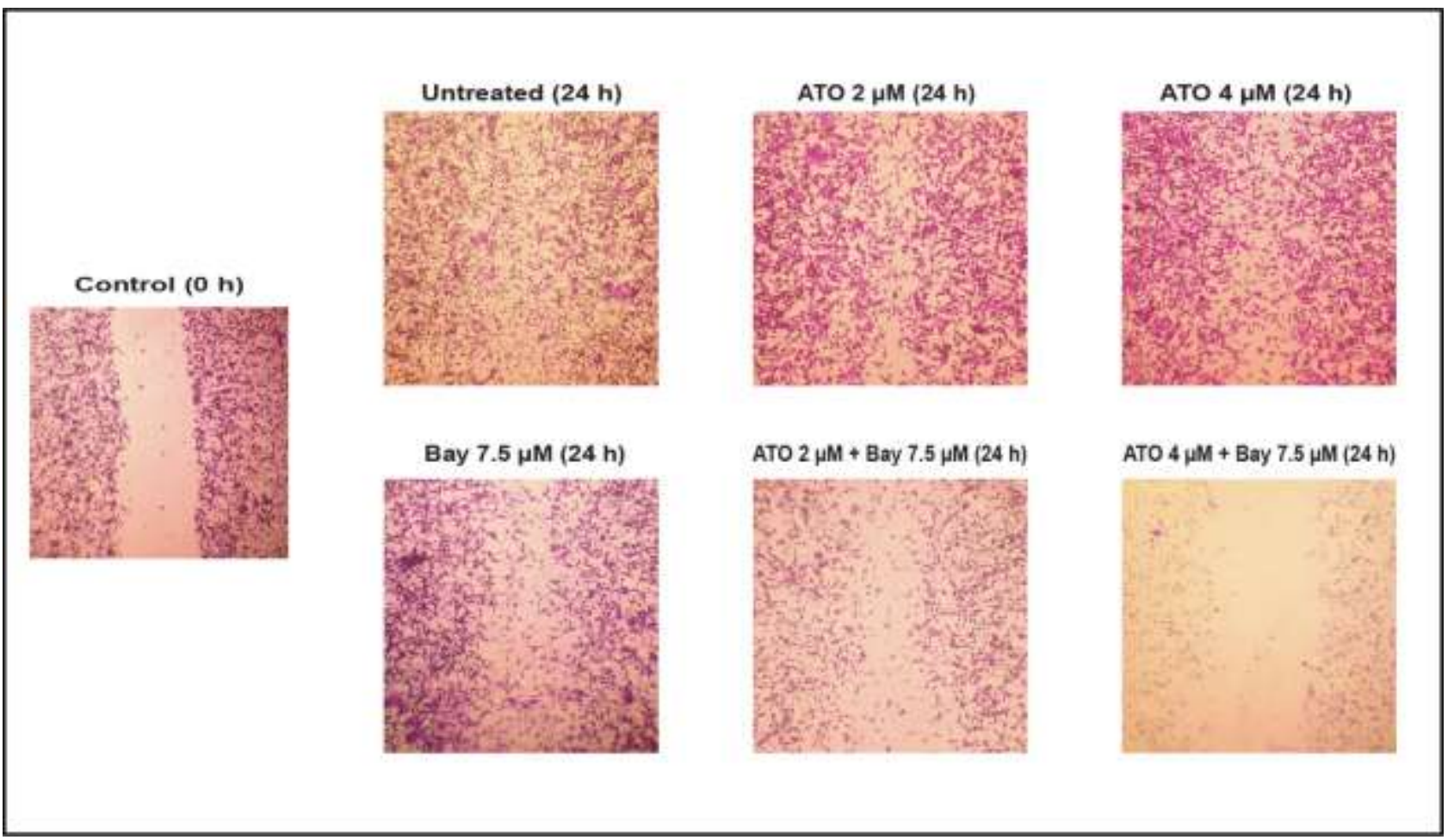

Fig. 3. ATO/Bay 11-7082 inhibited migration of U87 GBM cancer cells. The results of the scratch assay, according to the width of the gaps, showed that Bay 11-7082 at 7.5 $\mu \mathrm{M}$ concentration enhanced the inhibitory effects of ATO on migration abilities of U87 cells after $24 \mathrm{~h}$ treatment. 
Bay 11-7082 enhanced ATO-induced apoptotic cell death in U87 cells

To investigate whether NF- $\kappa \mathrm{B}$ inhibition enhanced the cytotoxic effects of ATO in U87 cells via induction of apoptosis, the percentage of apoptotic cells was measured using Annexin $\mathrm{V}$ staining. The results of flow cytometry confirmed that although mono treatment with

ATO and Bay 11-7082 can elevate the portion of apoptotic cells to $20 \%$ and $26 \%$ respectively, after co-treatment of U87 cells with both agents, $77 \%$ of cells have undergone apoptotic cell death, suggesting that the synergistic effects between ATO and Bay 11-7082 may be due to induction of apoptosis (Fig. 4).

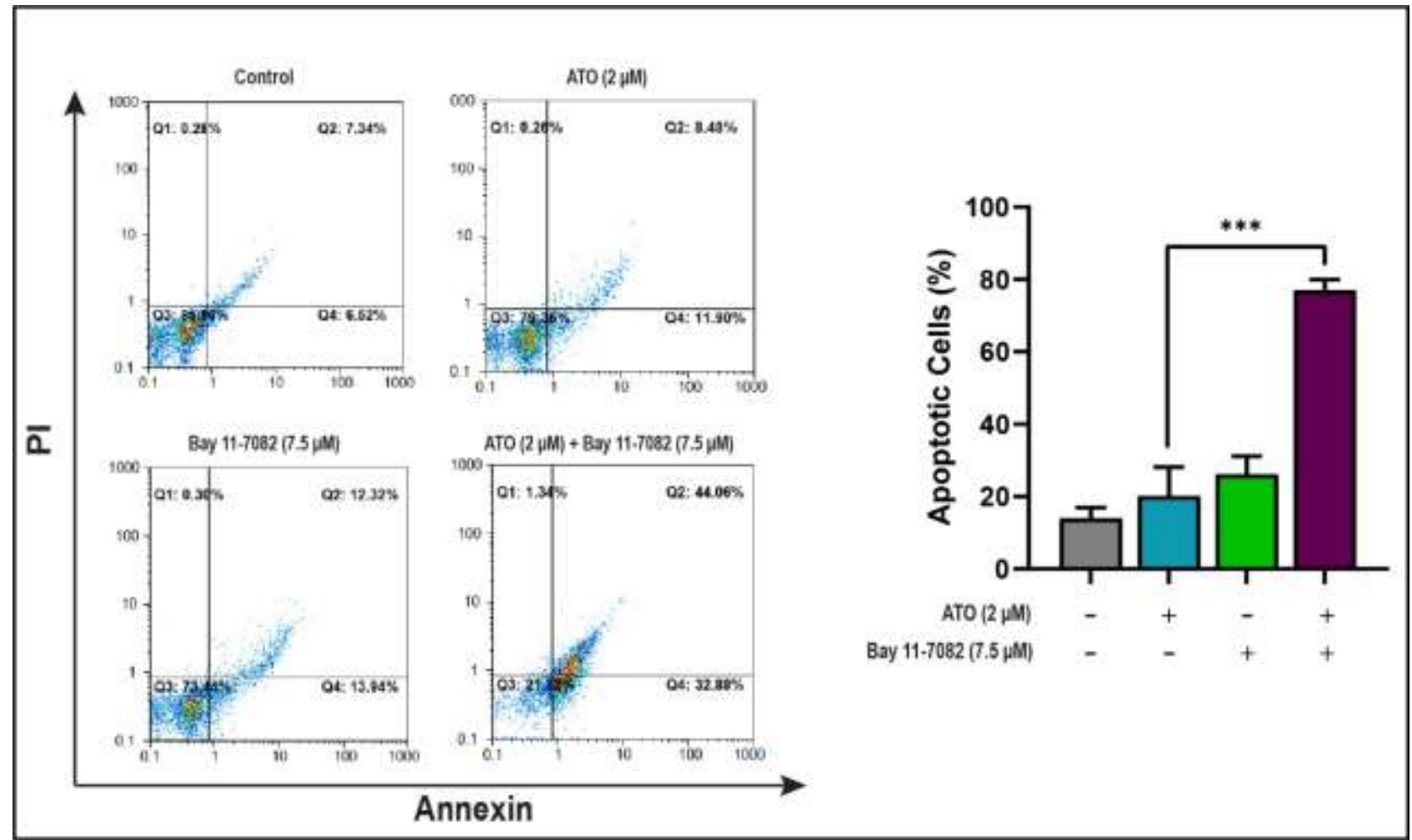

Fig. 4. NF- $\kappa B$ inhibition using Bay 11-7082 could enhance the ATO-induced apoptotic cell death in U87 cells. Data are shown as mean \pm S.D. of three independent experiments. Statistical significance was defined at $* * * p<0.001$.

ATO and Bay 11-7082 hinder the transcription of $\mathrm{NF}-\kappa \mathrm{B}$ target genes involved in metastasis and apoptosis

$\mathrm{NF}-\kappa \mathrm{B}$ promotes migration of cancer cells via induction of its downstream genes including Twist, MMP2, ICAM-1, and cathepsin B (23). Hence, we investigate the effects of ATO/Bay 11-7082 on the expression of the aforementioned genes in U87 cells using RTqPCR. Combination treatment with ATO and Bay 11-7082 significantly reduced the mRNA levels of Twist, MMP2, ICAM-1, and cathepsin $B$ compared to ATO-treated cells (Fig. 5a).

$\mathrm{NF}-\kappa \mathrm{B}$ directly regulates the transcription of several anti-apoptotic target genes such as
$B c l-2$ as well as inhibitor of apoptosis (IAP) family members (23). Based on this and the significant role of ATO/Bay 11-7082 in apoptosis induction, we sought whether NF$\kappa \mathrm{B}$ downstream genes are involved in apoptotic effects of combination therapy with ATO and Bay 11-7082. ATO/Bay 11-7082 inhibited the expression of Bcl-2, survivin, $X I A P, c-I A P 1$, and $c-I A P 2$ in U87 cells (Fig. $5 b)$. Altogether, these results suggest that the combination of ATO and BAY 11-7082 may suppress invasion and induce apoptosis in U87 GBM cells via downregulation of NF- $\mathrm{B}$ target genes. 


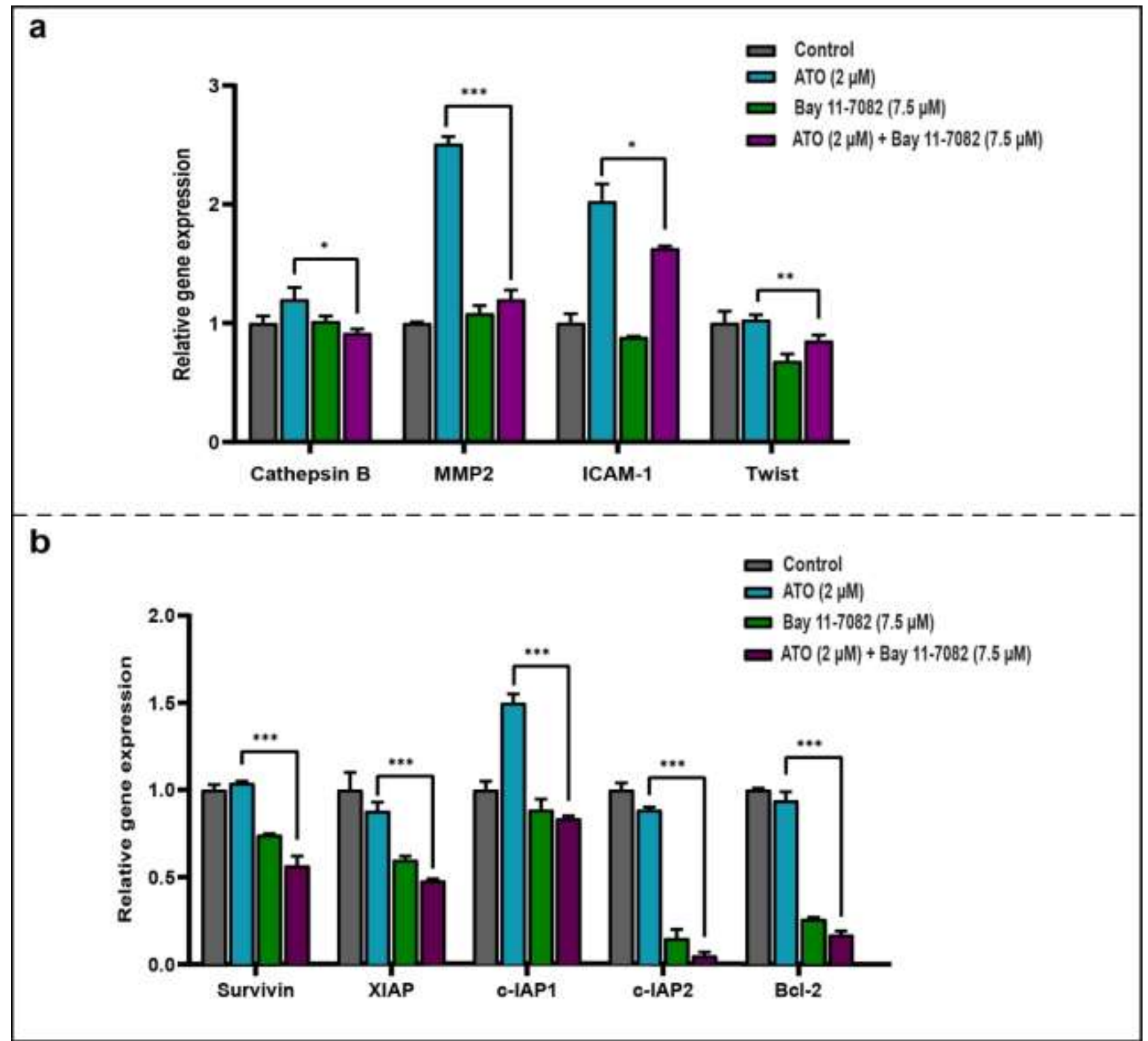

Fig. 5. Combination treatment with ATO and Bay 11-7082 inhibited the transcription of NF- $\kappa \mathrm{B}$ target genes involved in metastasis and apoptosis evasion in U87 cells. (a) The expression of metastasis-related target genes of NF- $\kappa \mathrm{B}$ including Twist, MMP2, ICAM-1, and cathepsin B was examined in U87 after a 24 h exposure to ATO/Bay 11-7082 using RTqPCR. (b) The expression of NF-кB anti-apoptotic target genes (Survivin, XIAP, c-IAP1, c-IAP2, and Bcl-2) was examined in U87 after a $24 \mathrm{~h}$ exposure to ATO/Bay 11-7082 using RT-qPCR. Values are given as mean \pm SD of three independent experiments. ${ }^{*} \mathrm{p}<0.05, * * \mathrm{p}<0.01$ and $* * * \mathrm{p}<0.001$ represents significant changes from untreated control.

\section{Discussion}

ATO, a clinically approved chemotherapeutic agent for the treatment of APL (7), has been found to induce antiproliferative activity in solid tumors such as glioblastoma (GBM). However, it has been shown that ATO at concentrations lower than $4 \mu \mathrm{M}$ cannot induce potent apoptotic cell death in GBM cells. Therefore, the limited success of ATO as a single agent at a clinical dose of $0.5-2 \mu \mathrm{M}$ in GBM has generated a great deal of interest in using ATO in combination with other anticancer agents to enhance its antitumor properties $(10,11)$. For instance, we have previously indicated that telomerase inhibition using BIBR1532 sensitizes breast cancer cells to low concentrations of ATO (24). In the case of GBM, erlotinib, an inhibitor of epidermal growth factor receptor (EGFR), has been found to enhance the cytotoxic effects of ATO (25). These findings suggest that using ATO in 
combination therapy with small molecule inhibitors is a promising strategy for treating GBM.

Previous studies have highlighted the association of deregulated NF- $\kappa \mathrm{B}$ signaling pathway with tumorigenesis. The activation of NF- $\kappa \mathrm{B}$ pathway in GBM is strongly correlated with shorter survival and considerable resistance to chemotherapy and radiation (15). There is evidence that suppression of $\mathrm{NF}-\kappa \mathrm{B}$ not only induces potent antitumor activity in cancer cells but also sensitizes them to chemotherapeutic agents (14). In one study, we showed the synergistic interactions between $\mathrm{NF}-\kappa \mathrm{B}$ inhibition by Bay 11-7082 and a panel of chemotherapy drugs including paclitaxel, cisplatin, and carboplatin (19). Furthermore, it has been demonstrated that Bay 11-7082 reverses resistance to temozolomide in human glioma cells (16). Based on these findings, was decided to evaluate the synergistic effects between ATO and Bay 11-7082 in GBM cells, where it was revealed that NF- $\kappa \mathrm{B}$ blockade using Bay 11-7082 synergistically enhances the ATO-induced antiproliferative activity in U87 glioma cells. These findings suggest that suppression of $\mathrm{NF}-\kappa \mathrm{B}$ may be an effective strategy to sensitize GBM cells to lower concentrations of ATO.

Aggressive invasion into surrounding tissues, a major hallmark of GBM, has limited the therapeutic options for this malignancy (26). It has been reported that RelB, a member of NF$\kappa \mathrm{B}$ family, promotes migration of GBM cells and its knockdown has been found to attenuate cell invasion and motility (27). In cancer cells, the process of metastasis can be positively regulated by NF- $\kappa \mathrm{B}$ through upregulation of its target genes including Twist, MMP2, ICAM-1, and cathepsin $B$ (27). Overexpression of Twist in glioma cell lines promotes tumor invasion and metastasis and is correlated with the highest grade gliomas (28). In addition, brain tumors with higher expression of $M M P 2$ are associated with higher degrees of invasion and metastasis (29). Another study has indicated that ICAM- 1 plays an important role in promoting tumor migration in bevacizumab-resistant glioblastoma and its knockdown inhibited cell motility in vitro and in vivo (30). It has been shown that the higher activity of cathepsin $B$ in glioma cells compared to adjacent normal brain tissues is a critical mediator of cell invasion. Moreover, inhibition of cathepsin B significantly diminished the migration and metastasis of glioma cells (31). In this context, we sought whether NF- $\kappa \mathrm{B}$ blockade using Bay 11-7082 enhances the inhibitory effects of ATO on the motility of U87 glioma cells. Our data displayed that ATO/Bay 11-7082 not only suppressed the invasion and metastasis of U87 cells but also decreased the mRNA levels of Twist, MMP2, ICAM-1, and cathepsin B compared to ATO-treated cells. Collectively, these findings suggest that combination therapy with ATO and Bay 11-7082 impairs the migration and metastasis of GBM cells through downregulation of NF- $\kappa \mathrm{B}$ target genes.

Previous studies have revealed that the deregulation of apoptosis in GBM is a formidable challenge for the treatment of this disease. It has been demonstrated that radiotherapy and antitumor drugs could not efficiently activate apoptotic pathways in gliomas which can lead to resistance to these therapeutic strategies $(32,33)$. Emerging evidence indicates the association between activation of NF- $\kappa \mathrm{B}$ signaling pathway and evasion of apoptosis in cancer cells. The inhibitory effect of this oncogenic pathway on apoptosis may be due to inducing the transcription of several anti-apoptotic target genes including $B c l$-2, survivin, XIAP, $c-I A P 1$, and $c$-IAP2 (23). One study showed that Bcl-2 is highly expressed in glioma malignancies and its inhibition can sensitize GBM cells to cytotoxic drugs (34). The overexpression of XIAP is correlated with poor prognosis in GBM patients (35). Moreover, XIAP inhibition has been found to overcome radiotherapy resistance in GBM through induction of apoptotic cell death (36). Another study has demonstrated that the mRNA level of survivin is negatively associated with overall survival in GBM patients (37). In this regard, it was of particular interest to examine whether NF- $\kappa \mathrm{B}$ inhibition enhances ATOinduced apoptotic cell death. The combination 
treatment with ATO and Bay 11-7082 significantly induces apoptosis in U87 cells, coupled with downregulation of $\mathrm{Bcl}-2$, survivin, XIAP, $c-I A P 1$, and $c-I A P 2$ genes, suggesting that ATO/Bay 11-7082 may trigger apoptotic cell death in U87 cells via suppressing the expression of NF- $\kappa \mathrm{B}$ antiapoptotic target genes. Taken together, our results indicate that $\mathrm{NF}-\kappa \mathrm{B}$ blockade using Bay 11-7082 may be a promising approach to sensitize GBM cells to lower concentration of ATO via downregulation of $\mathrm{NF}-\kappa \mathrm{B}$ target genes involved in metastasis and evasion of

\section{References}

1. Taylor OG, Brzozowski JS, Skelding KA. Glioblastoma multiforme: an overview of emerging therapeutic targets. Front Oncol. 2019;9:963.

2. Chen B, Chen C, Zhang Y, Xu J. Recent incidence trend of elderly patients with glioblastoma in the United States, 2000-2017. BMC cancer. 2021;21(1):1-10.

3. Lukas RV, Wainwright DA, Ladomersky E, Sachdev S, Sonabend AM, Stupp R. Newly diagnosed glioblastoma: a review on clinical management. Oncology (Williston Park). 2019;33(3):91-100.

4. Tan AC, Ashley DM, López GY, Malinzak M, Friedman HS, Khasraw M. Management of glioblastoma: State of the art and future directions. CA Cancer J Clin. 2020;70(4):299-312.

5. Iwamoto FM, Fine HA. Bevacizumab for malignant gliomas. Arch Neurol. 2010;67(3):285-288.

6. Tamimi AF, Juweid M, Vleeschouwer SD. Epidemiology and outcome of glioblastoma. Exon Publications. 2017:143-53.

7. Sanz MA, Fenaux P, Tallman MS, Estey EH, Löwenberg B, Naoe T, et al. Management of acute promyelocytic leukemia: updated recommendations from an expert panel of the European LeukemiaNet. Blood. 2019;133(15):1630-1643.

8. Leung LL, Lam SK, Li YY, Ho JCM. Tumour growth-suppressive effect of arsenic trioxide in squamous cell lung carcinoma. Oncol Lett. 2017;14(3):3748-3754. apoptosis, constructing an effective combination therapy for GBM. Further in vivo studies are required to confirm the antitumor activity of combination therapy with ATO and Bay 11-7082 in GBM.

\section{Acknowledgements}

This study was supported by a grant from Hematology, Oncology and Stem Cell Transplantation Research Center, Tehran University of Medical Sciences, Tehran, Iran [99-2-107-49326].

The authors declare no conflict of interest.

9. Zhang T, Wang S, Hong L, Wang X, Qi Q. Arsenic trioxide induces apoptosis of rat hepatocellular carcinoma cells in vivo. J Exp Clin Cancer Res. 2003;22(1):61-8.

10. Fang Y, Zhang Z. Arsenic trioxide as a novel anti-glioma drug: a review. Cell Mol Biol Lett. 2020;25:44.

11. Cheng Y, Li Y, Ma C, Song Y, Xu H, Yu H, et al. Arsenic trioxide inhibits glioma cell growth through induction of telomerase displacement and telomere dysfunction. Oncotarget. 2016;7(11):12682-92.

12. Osuka S, Van Meir EG. Overcoming therapeutic resistance in glioblastoma: the way forward. J Clin Invest. 2017;127(2):415-426.

13. Cahill KE, Morshed RA, Yamini B. Nuclear factor- $\mathrm{\kappa}$ B in glioblastoma: insights into regulators and targeted therapy. Neuro Oncol. 2015;18(3):329-39.

14. Puliyappadamba VT, Hatanpaa KJ, Chakraborty S, Habib AA. The role of NF- $\kappa B$ in the pathogenesis of glioma. Mol Cell Oncol. 2014;1(3):e963478.

15. Soubannier V, Stifani S. NF- $\kappa B$ signalling in glioblastoma. Biomedicines. 2017;5(2):29.

16. Avci NG, Ebrahimzadeh-Pustchi S, Akay YM, Esquenazi Y, Tandon N, Zhu J-J, et al. NF$\kappa \mathrm{B}$ inhibitor with Temozolomide results in significant apoptosis in glioblastoma via the NF$\kappa \mathrm{B}(\mathrm{p} 65)$ and actin cytoskeleton regulatory pathways. Scientific Reports. 2020;10(1):1-14.

17. Zanotto-Filho A, Braganhol E, Schröder R, de Souza LHT, Dalmolin RJ, Pasquali MAB, et al. NFkB inhibitors induce cell death in 
glioblastomas. Biochem Pharmacol. 2011;81(3):412-24.

18. Krishnan N, Bencze G, Cohen P, Tonks NK. The anti-inflammatory compound BAY-11-7082 is a potent inhibitor of protein tyrosine phosphatases. FEBS J. 2013;280(12):2830-2841. 19. Momeny M, Yousefi H, Eyvani H, Moghaddaskho F, Salehi A, Esmaeili F, et al. Blockade of nuclear factor- $\kappa \mathrm{B}(\mathrm{NF}-\kappa \mathrm{B})$ pathway inhibits growth and induces apoptosis in chemoresistant ovarian carcinoma cells. Int $\mathrm{J}$ Biochem Cell Biol. 2018;99:1-9.

20. Chou T-C. Drug combination studies and their synergy quantification using the ChouTalalay method. Cancer Res. 2010;70(2):440-6.

21. Baakhlagh S, Kashani B, Zandi Z, Bashash D, Moradkhani M, Nasrollahzadeh A, et al. Toll-like receptor 4 signaling pathway is correlated with pathophysiological characteristics of AML patients and its inhibition using TAK-242 suppresses AML cell proliferation. Int Immunopharmacol. 2020;90:107202.

22. Xia Y, Shen S, Verma IM. NF-kB, an active player in human cancers. Cancer Immunol Res. 2014;2(9):823-30.

23. Basseres D, Baldwin A. Nuclear factor- $\kappa$ B and inhibitor of $\kappa \mathrm{B}$ kinase pathways in oncogenic initiation and progression. Oncogene. 2006;25(51):6817-30.

24. Nasrollahzadeh A, Bashash D, Kabuli M, Zandi Z, Kashani B, Zaghal A, et al. Arsenic trioxide and BIBR1532 synergistically inhibit breast cancer cell proliferation through attenuation of NF- $\kappa B$ signaling pathway. Life Sci. 2020;257:118060.

25. Mesbahi Y, Zekri A, Ahmadian S, Alimoghaddam K, Ghavamzadeh A, Ghaffari $\mathrm{SH}$. Targeting of EGFR increase anti-cancer effects of arsenic trioxide: Promising treatment for glioblastoma multiform. Eur J Pharmacol. 2018;820:274-285.

26. Vollmann-Zwerenz A, Leidgens V, Feliciello G, Klein CA, Hau P. Tumor cell invasion in glioblastoma. Int J Mol Sci. 2020;21(6):1932.

27. Lee DW, Ramakrishnan D, Valenta J, Parney IF, Bayless KJ, Sitcheran R. The NF-кB RelB protein is an oncogenic driver of mesenchymal glioma. PloS one. 2013;8(2):e57489.
28. EliasM C, TozerK R. TWIST is Expressed in Human Gliomas and Promotes Invasion. Neoplasia. 2005;7(9):824-837.

29. Yu C-F, Chen F-H, Lu M-H, Hong J-H, Chiang C-S. Dual roles of tumour cells-derived matrix metalloproteinase 2 on brain tumour growth and invasion. $\mathrm{Br} \mathrm{J}$ Cancer. 2017;117(12):1828-1836.

30. Piao Y, Henry V, Tiao N, Park SY, MartinezLedesma J, Dong JW, et al. Targeting intercellular adhesion molecule-1 prolongs survival in mice bearing bevacizumab-resistant glioblastoma. Oncotarget. 2017;8(57):96970-96983.

31. Demchik LL, Sameni M, Nelson K, Mikkelsen T, Sloane BF. Cathepsin B and glioma invasion. Int J Dev Neurosci. 1999;17(56):483-94.

32. Valdés-Rives SA, Casique-Aguirre D, Germán-Castelán L, Velasco-Velázquez MA, González-Arenas A. Apoptotic signaling pathways in glioblastoma and therapeutic implications. Biomed Res Int. 2017;2017:7403747.

33. Steinbach JP, Weller M. Apoptosis in gliomas: molecular mechanisms and therapeutic implications. J Neurooncol. 2004;70(2):245-54.

34. Qiu B, Wang Y, Tao J, Wang Y. Expression and correlation of Bcl-2 with pathological grades in human glioma stem cells. Oncol Rep. 2012;28(1):155-60.

35. Emery IF, Gopalan A, Wood S, Chow K-h, Battelli C, George J, et al. Expression and function of ABCG 2 and XIAP in glioblastomas. $\mathrm{J}$ Neurooncol. 2017;133(1):47-57.

36. Vellanki SHK, Grabrucker A, Liebau S, Proepper C, Eramo A, Braun V, et al. Smallmolecule XIAP inhibitors enhance $\gamma$-irradiationinduced apoptosis in glioblastoma. Neoplasia. 2009;11(8):743-52.

37. Tong X, Yang P, Wang K, Liu Y, Liu X, Shan $\mathrm{X}$, et al. Survivin is a prognostic indicator in glioblastoma and may be a target of microRNA-218. Oncol Lett. 2019;18(1):359-367. 